\title{
Deliberative Democracy in Virtual Public Space: A Case Study of Semarang City's “LAPOR Hendi”
}

\author{
Yuwanto \\ \{yuwantosaja@gmail.com\} \\ Universitas Diponegoro, Indonesia
}

\begin{abstract}
This study aims to describe how digital public service innovation in Semarang City functions as a deliberative democratic public sphere. Deliberation is a necessary precondition for the legitimacy of democratic political decisions; and the advancement of modern technology has changed the patterns of state and society relationships. In this context, the internet has been regarded as a new form of public sphere and it could be an efficient political instrument. This paper argues that there are reasons to believe about the effectiveness of virtual public space as a fruitful way of deepening democracy by its deliberative practice. The research was conducted in Semarang City by focusing on "LAPOR Hendi" as a part of the Open Government Indonesia (OGI) Project; and using its digital media canals activities namely Twitter, Instagram, Telegram as a source of primary data. The results showed that the implementation of "LAPOR Hendi" has creatively brought most of innovation attributes i.e., relative advantage, compatibility, complexity, trialability, and observability; and those creativities implied to its role on the utilization of virtual public sphere for deliberative democracy practices. The role of "LAPOR Hendi" as a means of developing deliberative democracy can also be seen from its accessibility, range and rapidity. In conclusion, those findings generally confirmed that deliberative democracy has been nurtured, developed and improved through "LAPOR Hendi".
\end{abstract}

Keywords: Deliberative Democracy, Virtual Public Space, Public Policy, Participation

\section{Introduction}

Deliberative democracy is a form of democracy in which deliberation is central to decision making. It differs from traditional democratic theory in that authentic deliberation, not mere voting, is the primary source of legitimacy for the lawmaking processes. Authentic deliberation is deliberation among decision-makers that is free from distortions of unequal political power, such as power a decision-maker obtained through economic wealth or the support of interest groups [1]. If the decision-makers cannot reach consensus after authentically deliberating on a proposal, then they vote on the proposal using a form of majority rule. Cohen [2] introduces principles of deliberative democracy namely: (1) Citizens must decide that deliberation is the basis upon which all decisions must be based (2) Only decisions reached through this procedure can be taken as legitimate and worthy of pursuing (3) The process and procedures must be transparent and decisions must be easily traceable back to the deliberative process (4) There must be a commitment to respect the pluralism of values and aims as expressed by all, and (5) Each member and all members must be accorded equal opportunities to participate freely in the deliberative processes. 
Deliberative democracy can be improved in practical form by increasing the role of technology in governance, especially through virtual public space based on internet technology. By doing so, there will be more changes on the pattern of relationships between government and its citizens.

The process of adopting new innovations has been studied for over 30 years, and one of the most popular adoption models is described by Rogers [3] in his book, Diffusion of Innovations (2003). Much research from a broad variety of disciplines has used the model as a framework; including political science, public health, communications, history, economics, technology, and education. Shortly, Rogers [3] theory is widely used as a theoretical framework in the area of technology diffusion and adoption.

In this context, scholars and decision-makers are getting interested in developing the idea of open government with technology as the key element [4]. Open government as a governing concept not only holds that citizens have the right to access the documents and proceedings of the government to allow for effective public oversight; but also holds the importance of public participation and collaborations.

In 2011, government leaders and civil society advocates came together to create a unique partnership that combines these powerful forces to promote accountable, responsive and inclusive governance. Internationally, seventy-eight countries (including Indonesia) and a growing number of local governments along with thousands of civil society organizations became members of the Open Government Partnership (OGP).

In 2012 Indonesia formally launched Open Government Indonesia (OGI) with three programs on national level namely "Portal Satu Data" (One Data Portal), "Kebijakan Satu Peta" (One Map Policy), and "LAPOR" which stands for "Layanan Aspirasi dan Pengaduan Online Rakyat" (Aspiration Service and People's Online Complaint). Ever since, once in two years, Indonesian government and NGO's hold a meeting to arrange an open government action plan for various government institutions based on "co-creation principle."

"LAPOR Hendi" is a part of OGI and integrated with all of OGI's national programs, although it also has flexibility to improve and creates the contents. In short, "LAPOR Hendi" is open to utilize its digital technology (cyberspace) potentiality as a virtual public space in enhancing and accelerating the quality of public services.

This paper will describe how "LAPOR Hendi" is implemented and its role as a means of developing deliberative democracy through the enhancement of public participation and collaborations.

\section{Methodology}

The approach of this research is a descriptive-qualitative one and it focuses on the three canals of digital media employed by "LAPOR Hendi" i.e. Twitter, Instagram, and Telegram. By using those three canals we will reveal all of the implementation aspects of it. Informants are mainly choosed from related stakeholders which consists of the elements of local government namely Center for People Complaint Management (P3M), local NGO called Pattiro and public as user. Methods of data collections are interview, observation and documentation; and data analysis technique conducted interactively through steps namely data reduction, data presentation, and making conclusion. 


\section{Discussion}

\subsection{Findings}

Quantitatively, in 2019-2020 there were 3,392 reports, responses, input and the like to "LAPOR Hendi" through various available channels. Of the three canals provided, most of the responses were Instagram (1,712), Twitter (927), and Telegram (753) respectively. By using Rogers' [3] theoretical framework the results showed that the implementation of " $L A P O R$ Hendi" has creatively brought most of those innovation attributes i.e. relative advantage, compatibility, complexity, trialability, and observability. The findings can be described as follows: (a) Relative advantage. It measures how improved an innovation is over the previous generation of an innovation. Compare to the previous one, "LAPOR Hendi" has several advantages related to its degree of responsiveness in handling public complaints. By using three canals of digital media i.e., Twitter, Instagram, and Telegram; many kinds of complaint can be responded and solved much faster by the government office. However, "LAPOR" Hendi proved compatible with its previous digital public space innovation which mainly relied on conventional canals namely message, website or web portal. Instead, two kinds of innovation are complementary as they jointly provide more varied canals; and thereby more segments of inhabitant are covered by those two innovations. In addition to the compatibility, "LAPOR Hendi" also suitable with City's masterplan of becoming a Smart City (b) Compatibility. It refers to the assimilation of innovation into people's life and their lifestyle. This successful implementation of "LAPOR Hendi" is mostly benefited from the spreading a kind of the urban new which created "Internet culture" amongst the urban people. Besides, Semarang City government also persevered in improving the infrastructure of communication technology to provide a massive public Internet (free Wi-Fi) for its inhabitant; (c) Complexity. It refers to how difficult it is for people to learn to use an innovation. Against the backdrop, "LAPOR Hendi" is regarded as a quite simple in terms of its practical usage. Twitter and Instagram for instance, are commonly owned and used by most of people; (d) Trialability. It describes how easily people can explore the innovation. In this context of trialability, "LAPOR $H e n d i$ " was began to be implemented without any kind of test yet or even the phase of socalled "socialization" amongst inhabitant; (e) Observability. It is the extent to which the result or benefit of using "LAPOR Hendi" is visible to the people; and the result showed that most of users clearly see the benefit of using it. People can easily observe the procedures of both process and results of their complaints or reports in an interactive manner which already built in the digital canals. Everyone can seek and comments on the canals openly and freely; including doing verification on each of uploaded complaint or report.

\section{2 “LAPOR Hendi” as a Virtual Public Space}

Innovation of "LAPOR Hendi" can be an alternative space for a certain kind of public discussion amongst inhabitant. By utilizing internet technology, it paves the way for the practice of online deliberative democracy through its canals. Practically, all of about 1.6 million in habitant can be able to use those canals to submit or upload their aspirations related to any issues in day-to-day activities. Therefore, "LAPOR Hendi" convincingly can be assumed as a virtual public space. Virtual public space is a new public space that has emerged due to the role of the development of Internet technology; and it becomes as a new arena for the democratic process in the digital era. 
Before discussing any further of the role of "LAPOR Hendi" as a virtual public space, we need to examine the dimensions of virtual public space namely unlimited, universal, egalitarian, and interactive [5]. Firstly, the limitless of "LAPOR Hendi" because of its never stop accessibility regardless time and place; including out of its operating hours. Practically, all the time everybody can make a various interaction in this digital public place and those activities can still be tracked observed and responded. Secondly, everyone has the same opportunity to access "LAPOR Hendi" without any requirements imposed on them; even if they do not use the authentic identities. In addition, all of complaint and reports will be proceed by the authorities. Thirdly, for the sake of equality principle, there is no privileges or special treatment are given to a certain people. However, the authorities emphasized the importance of "tangible evidence" whenever people complaint or report about something physical, for example city's infrastructure and public transportation. Fourthly, "LAPOR Hendi" is dynamically creates interactions that are not only two-ways, but in many directions. Unlike telephone and text massage, interactions in digital social media can occur between the government and its citizens, amongst the government agencies, and amongst the community. In brief, "LAPOR Hendi" can be seen as a virtual public space since all of its dimensions are completely fulfilled.

\subsection{The Role of "LAPOR Hendi" as a Virtual Public Space}

After confirming "LAPOR Hendi" as a virtual public space, then we can easier describe its role on public policy, especially on the phase of implementation, evaluation and revision. Overall, the role of "LAPOR Hendi" is indicated by its accessibility, range and rapidity. In terms of accessibility, this virtual public space provides a broad access for the public in conveying aspirations and complaints about City's government performance. It has succeeded in increasing the compatibility between services and its purposes, since the more social media canals had been added the wider access can be used by more people. For instance, to make reports on social media, people only need to use the hashtag \#LaporHendi on Twitter or comment on the Mayor's Instagram account.

With regard to the range of innovation, "LAPOR Hendi" reaches a very broad population and it can be easily monitored by the public as well. Furthermore, amongst the three canals, Twitter and Instagram are the most popular one and became a main of virtual public space.

Lastly, rapidity of "LAPOR Hendi" is reflected on the increasing speed in receiving and responding all kinds of complaints and reports.

These trends indicate that people are getting familiar with a virtual public space; and there is reason to believe that such a trend may have a profound role on the relationship between the public and government in deliberative manner.

"LAPOR Hendi" which allows for a free and transparent interpersonal communication through its provided canals encouraged people to participate in almost every aspects of government activities. Individuals can now articulate their own interests, aspirations, or just a point of view using those canals in virtual public space.

In a broader sense, "LAPOR Hendi" has the potential for enhancing the essence of deliberation democracy such as political discussion, knowledge, and interest. 


\section{Conclusion}

In terms of informal civic practices, acknowledgement to the Internet as a means for the expansion of citizen deliberation leading to the formation of rational public opinion through which official decision makers can be held accountable. "LAPOR Hendi" as a form of deliberative democracy in virtual public space which initiated by Semarang City government has been proved in fulfilling most of attributes of public policy innovation namely relative advantage, compatibility, complexity, trial ability, and observe ability. Besides, it also substantiates four dimensions of virtual public space i.e., unrestricted, universal, equal, and interactive. By having those qualities, "LAPOR Hendi" also shows the capacity in improving public participation because of its effectively, accessibility, scope and rapidity. In general, those findings confirmed that deliberative democracy has been nurtured, developed and improved through "LAPOR Hendi."

\section{References}

[1] S. Threlkeld, "A blueprint for democratic law-making: give citizen juries the final say," Soc. Policy, vol. 28, no. 4, pp. 5-10, 1998.

[2] J. Cohen, "Deliberative Democracy \& Democratic Legitimacy" in Hamlin, A. \& Pettit, P. (eds.) The Good Polity. Oxford: Blackwell.," 1989.

[3] E. M. Rogers, "Diffusion of innovations, 5th edn Tampa," FL Free Press. Sch., 2003.

[4] B. W. Wirtz and S. Birkmeyer, "Open government: Origin, development, and conceptual perspectives," Int. J. Public Adm., vol. 38, no. 5, pp. 381-396, 2015.

[5] J. C. Correia, "The Meanings of Public Sphere: is there any democratic role for Internet," Correia, JC Maia, R.(eds)(2011), Public Sph. Reconsidered. Theor. Pract. Covilhã LabCom Books, 2011. 